\title{
Concurrent Hyperthyroidism and Papillary Thyroid Cancer
}

\author{
Gagliano E*, Sturniolo G, Querci A, Milone A, Paparo D, Ricciardello D, Vermiglio F and Barbuscia MA
}

Department of General Surgery, University of Messina, Italy

\begin{abstract}
Background: Concurrent thyroid cancer $(\mathrm{TC})$ and hyperthyroidism $(\mathrm{HT})$ is rare, though increasingly being reported. Ht due to TC is much rarer and more challenging.

Case presentation: We present a 35-year-old woman who had been on irregular regimens of propanolol and digoxin as treatment for worsening palpitations for 12 months. She came to our district hospital for her propanolol madication refil. We identified features of ht and found a left uninodular goiter with no cervical lymphadenopathy. She was referred for thyroid assessment which suggested primary HT and an enlarged heterogeneous left lobe with a well-defined homogenous solid mass. We restarted her on propanolol and referred her for a course of methimazole. Aqt the referral hospital she also underwent a left thyroid lobectomy. The resected lobe was sent for histopathology which revealed a neoplastic nodule with features suggestive of a papillary thyroid cancer (PTC) causing HT. The patient's clinical progress postoperatively was good and there was regression of hyperthyroidism.
\end{abstract}

Conclusions: The historical, clinical, and laboratory findings were suggestive of HT due to PTC. A high index of suspicion, prompt referral and counter-referral lead to a positive outcome of such a rare case. We advocate for systematic and careful evaluation of all thyroid nodules.

Keywords: Thyroid cancer; Hyperthyroidism; Papillary thyroid cancer; TSH

Abbreviations: HT: Hyperthyroidism; PTC: Papillary thyroid cancer; TC: Thyroid cancer; TSH: Thyroid stimulating hormone; Pt2n0m0: tumour node metastasis of the tnm grading system; CAMP: Cyclic adenosine monophosphate

\section{Case Report}

We present a 35-year-old woman from Sicily (Italy) endemic region for hyperthyroidism, came to the outpatient department of our policlinic university at Messina for a refill of her propanolol medication. She reported taking the drug routinely for palpitations. She reported taking the drug well until 12 months prior to presentation when she suddenly aware of her heartbeat. It had been recurrent and lasting several minutes each time it occurred. It became associated with dyspnoea initially moderate and then on mild exertion. After consulting at various health facilities in the north east of Italy, she was prescribed long-term, irregular and alternate daily regimens of $40 \mathrm{mg}$ propanolol and $0.25 \mathrm{mg}$ digoxin. Although the medications conferred her some relieve, she noticed progressive weight loss over the 12 months period from $90 \mathrm{~kg}$ to $62 \mathrm{~kg}$ despite an abnormal increase in her appetite for food. She also experienced frequent watery stools (averagely 6 times daily) $[1,2]$. She complained of heat intolerance and profuse sweating resulting in sleeping with minimal clothing. In addition, she noticed spontaneous resting tremors of her hands. Three months prior to presentation at our hospital, she noticed a painless lump on her neck that progressively increased in size. On reviewing her medical records, we noticed a number of investigations requested at various hospitals which she visited during the 8 months preceding her presentation at our hospital $[3,4]$. These included electrocardiographs, echocardiograms, full blood tests, fasting blood sugar, thyroid hormone assays, which were all without particularity also if the electrocardiography results which always showed a sinus tachycardia. She has no know history of exposure to radiations or family history of malignancies. Physical examination revealed a chronically ill-looking middle aged woman. Her eyes were normal, her voice was clear. She had fine resting tremors of her hands with her arms outstretched. There was a left anterolateral neck mass measuring $4 \times 3 \mathrm{~cm}$. The mass was mobile, non-tender, moved with swallowing, and not fixed to overlying or underlying tissue. No bruit was heard over the mass. There was no palpable cervical lymphadenopathy [5-7]. Her BMI was $20.1 \mathrm{~kg} / \mathrm{m}^{2}$. There was discrete bilateral pedal pitting oedema. The rest of the physical examination was without notable findings. In view of this presentation, a presumptive diagnosis of ht was made and we placed her on propanolol, $40 \mathrm{mg}$ twice daily. To confirm the diagnosis, we requested for a functional (serum T3,T4, TSH and ultrasound of the thyroid. The patient after done the structural assessment of the thyroid (ultrasound scan): the left thyroid lobe appeared enlarged, heterogeneous, with a fairly iso-echoic, well-defined homogenous solid mass. The right lobe was without particularity. No cervical lymphadenopathy was observed (Table 1) $[8,9]$.

In view of these findings, we concluded on a primary ht most likely due to a toxic uninodular goiter. She was placed on $60 \mathrm{mg}$ methimazole daily, 4 weeks after which she underwent a left thyroid lobectomy. The resected lobe was sent for histopathology. The postoperative course was uneventful.

The lobe weighed $33.5 \mathrm{~g}$ was received in formalin as two grey-tan soft tissue fragments. Cutting demonstrated a red tan cut surface with a

\begin{tabular}{|c|c|c|c|}
\hline Test & Results & Normal Range & Comment \\
\hline T3 & $>5.0$ & $(0.8-2.0) \mathrm{ng} / \mathrm{mL}$ & Elevated \\
\hline T4 & 23.3 & $(5.0-13.0) \mathrm{mg} / \mathrm{mg} / \mathrm{dL}$ & Elevated \\
\hline TSH & 0.13 & $(0.4-7.0) \mathrm{mlU} / \mathrm{mL}$ & Low \\
\hline \multicolumn{3}{|c|}{ Table 1: Functional assessment of the thyroid gland. }
\end{tabular}

*Corresponding author: Gagliano E, Department of General Surgery, University of Messina98124 Messina, Italy, Tel: 39090221380; E-mail: egagliano@unime.it

Received June 04, 2016; Accepted November 17, 2016; Published November 27, 2016

Citation: Gagliano E, Sturniolo G, Querci A, Milone A, Paparo D, et al. (2016) Concurrent Hyperthyroidism and Papillary Thyroid Cancer. Med Rep Case Stud 1: 123. doi: $10.4172 / 2572-5130.1000123$

Copyright: (c) 2016 Gagliano E, et al. This is an open-access article distributed under the terms of the Creative Commons Attribution License, which permits unrestricted use, distribution, and reproduction in any medium, provided the original author and source are credited. 
$3 \times 2.3 \times 2 \mathrm{~cm}$ nodule inside the bigger piece. Microscopic examination of representative sections of the large fragment with a full thickness section of the nodular structure revealed a nodular proliferation of enlarged pale cells with marginated chromatin and overlapping nuclei. Pink "bubble-gum"- like colloid was focally noted. The lesion was partially encapsulated and displayed areas with fibrosis and more follicular appearance of the aggregates. Based on these, a histological diagnosis of PTC (pt2n0m0) was made $[10,11]$.

We monitored the patient through scheduled regular visits and referrals. We observed a progressive decline in hyperthyroid symptoms and signs: the palpitations regressed as well as the diarrhoea and polyphagia, the heat intolerance regressed and one month postoperatively, her weight increased from $62 \mathrm{~kg}$ to $72 \mathrm{~kg}$. Functional assessment of the thyroid: levels of serum T3, T4 and TSH [12].

\section{Discussion}

We report a fortuitous finding of concurrent ht and PTC from a resource-limited setting. It is a challenge to manage. Grave's disease though the most common cause of HT, is less likely the diagnosis since the goiter was not diffuse, the eyes were normal and there was no pretibial myxoedema. A hyperfunctioning thyroid nodule therefore took precedence as the probable aetiological diagnosis, with a toxic adenoma being the most likely aetiology. Since the patient's TSH levels were low, the most appropriate next step would have been a thyroid scan (scintigraphy) to determine if the nodule is hot. That notwithstanding, even if the HT were due to a hyper functioning nodule, it is very rare for such a nodule to have malignant potentials, thus, they are seldom biopsied after scintigraphy. In the management of this case is that though histopathology can be done on a resected lobe, histopathology through fine needle aspiration cytology would have allowed for proper planning of the surgical approach to be used $[13,14]$. This is because it is suggested that toxic thyroid cancers are best treated by total thiroidectomy while incidental carcinomas can be managed by subtotal thyroidectomy or lobectomy. Histopathology revealed a PTC. Given the partial encapsulation of the neoplastic nodule in this case, the lesion could be further classified as an encapsulated variant of PTC. The differential diagnosis also included follicular adenoma with papillary hyperplasia but the extensive nuclear changes observed were typical of PTC (pt2n0m0). This case is again unusual in that most malignant thyroid tumours associated with HT that have been reported so far are papillari thyroid microcarcinomas (nodule $<1 \mathrm{~cm}$ or PT1). The many follicular cells observed in the neoplastic lesion were suggestive of follicular hyperactivity which is seen in toxic TC. If HT is due a tumour cell mass, demonstrated in most cases by clinical-histopathological correlation, a toxic TC is diagnosed. An ambiguity, however, remains because a scintigraphically hot nodule was not confirmed. Concomitant TC and HT can either be in the form of a fortuitous malignancy in the thyroid gland of a clinically hyperthyroid patient or as a TC presenting with HT with the latter being rarer. The two can be distinguished via histopathology, with lack of hyperplastic thyroid tissue suggesting a hyper functioning TC as in the case presented. Again, with retrospect to the lack of ultrasound findings of increase vascularity and diffuse enlargement of thyroid tissue, further credence is lent to the autonomous nature of the tumour cell mass. In terms of risk factors, based on the study by Mirfakhraee [1] patients with malignant hot nodules seem more likely to be younger and females as in the case the patient presented. HT due to TC is explained by somatic mutations in TSH receptor genes of the cancer cells. These mutations lead to constitutive activation of intracellular cyclic adenosine monophosphate (CAMP) cascade which induces hormonogenesis and thus HT [15].

\section{Conclusions}

The historical, clinical and laboratory findings of the case we report concurred with HT due to PTC. A high index of suspicion should be the attitude towards every thyroid nodule. A good referral and counterreferral system lead to a positive outcome. We advocate for systematic and careful evaluation of all thyroid nodules.

\section{Consent}

Written informed consent was obtained from the patient for publication of this case report.

\section{Competing Interest}

The authors declare that they have no competing interests.

\section{References}

1. Mirfakhraee S, Mathews D, Peng L, Woodruff S, Zigman JM (2013) A solitary hyperfunctioning thyroid nodule harbouring thyroid carcinoma: review of the literature. Thyroid Res J 6:7.

2. Vaiana R, Cappelli C, Perini P, Pinelli D, Camoni G, et al. (1999) Hyperthyroidism and Concurrent Thyroid. Cancer Tumori 85: 247-252.

3. Ruggieri M, Scocchiera F, Genderini M, Mascaro A, Luongo B, et al. (1999) Hyperthyroidism and concurrent thyroid carcinoma. Eur Rev Med Pharmacol Sci 3: 265-268.

4. Topaloğlu O, Çakır B, Dirikoç A, Aydın C, Ağaç T, et al. (2007) Case Report: A Patient with Severe Graves' Ophthalmopathy and Follicular Carcinoma. Turkish Journal of Endocrinology and Metabolism 11: 101-104.

5. Smith M, McHenry C, Jarosz H, Lawrence AM, Paloyan E (1988) Carcinoma of the thyroid in patients with autonomous nodules. Am Surg 54: 448-449.

6. Rieger R, Pimplo W, Money S, Rettenbacher L, Galvan G (1989) Hyperthyroidism and concurrent thyroid malignancies. Surgery 106: 6-10.

7. Ahuja S, Ernst H (1991)Hyperthyroidism and thyroid carcinoma. Acta Endocrinol 124: 146-151.

8. Chao TC, Lin JD, Jeng LB, Chen MF (1999) Thyroid cancer with concurrent hyperthyroidism. Arch Surg 134: 130-134.

9. Gabriele R, Letizia C, Borghese M, De Toma G, Celi M, et al. (2003) Thyroid cancer in patients with hyperthyroidism. Horm Res 60: 79-83.

10. Guinet P, Tourniaire J, Radi A, Briere J, Bryon PA, et al. (1972) Hyperthyroidism and thyroid cancer. Endocrinol Clin 13: 199-227.

11. Abdel-Razzak M, Christie JH (1979) Thyroid carcinoma in an autonomously functioning nodule. J Nucl Med 20: 1001-1002.

12. Ahuija S, Ernst H (1991) Cytogenetic damage after 131-iodine treatment for hyperthyroidism and thyroid cancer. Acta Endocrinol 124: 146-151.

13. Behar R, Arganini M, Wu TC, McCormick M, Straus FH, et al. (1986) Graves disease and thyroid cancer. Surgery 100: 1121-1127.

14. Gabriele R, Letizia C, Borghese M, Tomo G (2003) Increased Aggressiveness of Thyroid Cancer in Patients with Graves' Disease. Horm Res 60: 79-83.

15. Pacini F, Elisei R, Di Coscio GC, Anelli S, Macchia E, et al. (1998) Thyroid carcinoma in thyrotoxic patients treated by surgery. J Endocrinol Invest 11 107-112. 